\title{
SCN VIP Neurons Are Essential for Normal Light-Mediated Resetting of the Circadian System
}

\author{
๑Jeff R. Jones, ${ }^{1}$ Tatiana Simon, ${ }^{1}$ Lorenzo Lones, ${ }^{2}$ and ${ }^{\circ}$ Erik D. Herzog ${ }^{1}$ \\ ${ }^{1}$ Department of Biology and ${ }^{2}$ Neuroscience Graduate Program, Washington University in St. Louis, St. Louis, Missouri 63130
}

The suprachiasmatic nucleus (SCN) synchronizes circadian rhythms in behavior and physiology to the external light cycle, but the mechanisms by which this occurs are unclear. As the neuropeptide vasoactive intestinal peptide (VIP) is important for circadian light responses, we tested the hypothesis that rhythmic VIP-producing SCN neurons mediate circadian light responses in male and female mice. Using in vivo fiber photometry over multiple days, we found daily rhythms in spontaneous calcium events of SCN VIP neurons that peaked during the subjective day and were disrupted by constant light. The light-evoked calcium responses peaked around subjective dusk and were greater during the subjective night. Using novel VIP sensor cells, we found that the activity patterns in SCN VIP neurons correlated tightly with spontaneous and NMDA-evoked VIP release. Finally, in vivo hyperpolarization of VIP neurons attenuated lightinduced shifts of daily rhythms in locomotion. We conclude that SCN VIP neurons exhibit circadian rhythms in spontaneous and light-responsive activity and are essential for the normal resetting of daily rhythms by environmental light.

Key words: calcium; circadian; light; neuropeptide; suprachiasmatic; vasoactive intestinal peptide

\section{Significance Statement}

Daily rhythms in behavior and physiology, including sleep/wake and hormone release, are synchronized to local time by the master circadian pacemaker, the suprachiasmatic nucleus (SCN). The advent of artificial lighting and, consequently, light exposure at night, is associated with an increased risk of disease due to disrupted circadian rhythms. However, the mechanisms by which the SCN encodes normal and pathological light information are unclear. Here, we find that vasoactive intestinal peptide (VIP)-producing SCN neurons exhibit daily rhythms in neuronal activity and VIP release, and that blocking the activity of these neurons attenuates light-induced phase shifts. We conclude that rhythmic VIP neurons are an essential component of the circadian light transduction pathway.

\section{Introduction}

Organisms have evolved endogenous circadian $(\sim 24 \mathrm{~h})$ rhythms in behavior and physiology, including sleep/wake, hormone release, and metabolism (Kalsbeek et al., 2006), to anticipate reliable daily events such as the light cycle. In mammals, light at night, but not during the day, shifts a master circadian pacemaker in the suprachiasmatic nucleus (SCN) to entrain daily rhythms to local time (Gillette, 1996; Sakamoto et al., 2013). Phase-

Received May 23, 2018; revised July 10, 2018; accepted July 14, 2018.

Author contributions: J.R.J. and E.D.H. designed research; J.R.J., T.S., and L.L. performed research; J.R.J., L.L., and E.D.H. analyzed data; J.R.J. wrote the paper.

This work is supported by National Institutes of Health Grants R01-NS-09536702 (E.D.H), U01-EB-02195601 (E.D.H), and F32-HL-133772 (J.R.J). We thank A. Damato (Washington U., St. Louis, MO, USA) for assistance with chemogenetics experiments, J. Webb (UCSF, San Francisco, CA, USA) for assistance with the neuropeptide sensor experiments, and the members of the Herzog laboratory and the Washington University Clocks and Sleep Club for discussion of and comments on the manuscript.

The authors declare no competing financial interests.

Correspondence should be addressed to Erik D. Herzog, Department of Biology, Box 1137, Washington University in St. Louis, St. Louis, M0, 63130. E-mail: herzog@wustl.edu.

DOI:10.1523/JNEUROSCI.1322-18.2018

Copyright $\odot 2018$ the authors $\quad 0270-6474 / 18 / 387986-10 \$ 15.00 / 0$ shifting environmental light is transduced to the SCN through melanopsin-containing, intrinsically photosensitive retinal ganglion cells through the release of glutamate and, perhaps, the neuropeptide PACAP to increase the firing rate of SCN neurons (Ibata et al., 1989; Meijer et al., 1993; Michel et al., 2006; Morin and Allen, 2006; Fernandez et al., 2016). This increase in firing rate increases intracellular calcium (Irwin and Allen, 2007), which activates a signaling cascade that shifts the neuron's molecular clock (Nitabach et al., 2002; Yamaguchi et al., 2003; Jones et al., 2015), ultimately shifting behavioral and physiological rhythms. Thus, the SCN is able to encode changes in environmental light that occur during, for instance, seasonal changes in the wild (Lucassen et al., 2012), but is limited in its ability to track larger shifts associated with jet lag or shift work schedules (Sack et al., 2007). Importantly, chronic nocturnal light exposure disrupts circadian rhythms in the SCN and behavior (Granados-Fuentes et al., 2004; Ohta et al., 2005) and is associated with an increased risk of disease (Fonken et al., 2010; LeGates et al., 2012; Chang et al., 2015; Lucassen et al., 2016). We do not know, however, which cell types mediate normal and pathological phototransduction in the SCN. 
The neuropeptide vasoactive intestinal peptide (VIP), produced by retinorecipient neurons comprising $\sim 10 \%$ of the SCN network, is the predominant contributor to synchrony in the SCN (Abrahamson and Moore, 2001; Colwell et al., 2003; Aton et al., 2005; Maywood et al., 2011) and has been implicated in photoentrainment. For instance, exogenous VIP administration can cause circadian phase shifts both in vitro and in vivo (Piggins et al., 1995; Reed et al., 2001; Atkins et al., 2010; An et al., 2011), and $\mathrm{Vip}^{-1-}$ mice start their daily activity $\sim 8 \mathrm{~h}$ earlier than wild-type mice (Colwell et al., 2003; Vosko et al., 2015). Because phaseshifting light pulses upregulate markers of neuronal activation in VIP neurons (Romijn et al., 1996; Kuhlman et al., 2003), we tested the hypothesis that VIP neurons mediate light responses in the SCN. Furthermore, we sought to clarify whether VIP neuron activity varies with time of day in vivo given the equivocal in vitro evidence (Fan et al., 2015; Hermanstyne et al., 2016; Enoki et al., 2017). Finally, we developed a novel measure of VIP release to address the questions of if and when SCN neurons release VIP spontaneously and in response to stimulation. We found that SCN VIP neurons are circadian and excited by light in vivo, release VIP depending on time of day and excitatory input, and are necessary for the normal transduction of light signals to the SCN at times when light shifts daily rhythms.

\section{Materials and Methods}

Animals. All experiments were performed using approximately equal numbers of male and female mice in accordance with the Washington University Institutional Animal Care and Use Committee guidelines. No differences in results were observed between sexes. For in vivo fiber photometry and chemogenetics experiments, we used heterozygous VIP-IRES-Cre knock-in mice $\left(V i p^{t m 1(c r e) Z j h} / J\right.$; catalog \#010908, The Jackson Laboratory; RRID:IMSR_JAX:010908; Taniguchi et al., 2011) on a C57BL/6JN background that were at least 6 weeks old at the time of virus injection and $\sim 2-5$ months old during recordings. To help identify VIP cells in some experiments, mice were crossed to Ai9 or

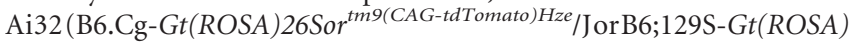
26 Sor $^{\text {tm } 32\left(C A G-C O P 4^{*} H 134 R / E Y F P\right) H z e} / \mathrm{J}$; catalog \#007909 or \#012569, The Jackson Laboratory; RRID:IMSR_JAX:007909 or IMSR_JAX:012569) mice to yield heterozygous VIP-IRES-Cre; Ai9 or VIP-IRES-Cre; Ai32 mice that expressed a tdTomato or enhanced yellow fluorescent protein fluorescent reporter in VIP neurons. For in vitro SCN recordings, we collected SCN slices from wild-type or Vip ${ }^{-1-}$ (founders were provided by C. Colwell, University of California, Los Angeles, Los Angeles, CA; RRID:IMSR_JAX:009640) mice (17-50 d old) on a C57BL/6JN background. After weaning and before recording, up to 5 mice of the same sex were housed per cage in a $12 \mathrm{~h}$ light/dark [LD; where lights on is defined as zeitgeber time (ZT) 0 ; light intensity $\sim 2 \times 10^{14}$ photons $/ \mathrm{cm}^{2} / \mathrm{s}$ ] cycle with food and water available ad libitum and constant temperature $\left(\sim 22^{\circ} \mathrm{C}\right)$ and humidity $(\sim 40 \%)$.

Virus injection and stereotaxic surgery. Cre-inducible adeno-associated virus (AAV) vectors encoding GCaMP6s (AAV9-CAG-Flex-GCaMP6sWPRE-SV40) and EGFP (AAV9-CAG-Flex-EGFP-WPRE-bGH) were obtained from the University of Pennsylvania Vector Core (AV-9ALL854 and AV-9-PV2818) and used at a final concentration of $\sim 1 \times$ $10^{13}$ genome copies $(\mathrm{GC}) / \mathrm{ml}$. Cre-inducible AAV vectors encoding hM4Di (AAV8-hSyn-DIO-hM4D $\left(\mathrm{G}_{\mathrm{i}}\right)$-mCherry) were obtained from Addgene (catalog \#44362) and used at a final concentration of $\sim 2 \times 10^{12}$ $\mathrm{GC} / \mathrm{ml}$. At the start of surgery, mice received preoperative analgesia (carprofen, $5 \mathrm{mg} / \mathrm{kg}$ ), were anesthetized with isoflurane (induction dose, $\sim 3 \%$; maintenance dose, $\sim 1.5 \%$ ), and placed in a stereotaxic frame (Kopf) on a heating pad to maintain body temperature throughout the procedure. We then infused virus to the SCN $(-0.46 \mathrm{~mm}$ posterior, $\pm 0.15 \mathrm{~mm}$ lateral, $-5.65 \mathrm{~mm}$ ventral from bregma) at a rate of 0.05 $\mu \mathrm{l} / \mathrm{min}$ through a 30 gauge needle attached to a $2 \mu \mathrm{l}$ syringe (Neuros, Hamilton). The total volume injected for fiber photometry experiments was $0.3 \mu$ l unilaterally (GCaMP6s and EGFP) and, for chemogenetics experiments, was 0.3 or $0.5 \mu$ l bilaterally (EGFP or hM4Di, respectively). After infusion, the needle was left in place for at least $8 \mathrm{~min}$ before slowly being withdrawn. For fiber photometry experiments, we subsequently implanted a fiber-optic cannula [6 $\mathrm{mm}$ in length; $400-\mu \mathrm{m}$-diameter core; 0.48 numerical aperture (NA); metal ferrule; Doric Lenses] immediately dorsal to the virus injection site. Cannulas were secured with a layer of adhesive cement (C\&B Metabond, Parkell) followed by a layer of opaque black dental cement (Ortho-Jet, Lang). After surgery, skin was closed with sutures or surgical glue (Vetbond, $3 \mathrm{M}$ ) and mice were allowed to recover on a heating pad until ambulatory. Mice were then transferred to their home cages for 2-4 weeks to allow for virus expression.

In vivo fiber photometry recording. After recovery and virus expression, mice were transferred to individual, open-topped cages equipped with running wheels and bedding maintained in a light-, temperature-, and humidity-controlled chamber with food and water available ad libitum. Lights were set to $12 \mathrm{~h} \mathrm{LD}$, constant darkness (DD), or constant light (LL; light intensity, $\sim 2 \times 10^{14}$ photons $/ \mathrm{cm}^{2} / \mathrm{s}$ ). Freely moving mice were chronically tethered to a fiber-optic cable ( $400 \mu \mathrm{m}$ core; $0.48 \mathrm{NA} ; 1.5 \mathrm{~m}$ in length; Doric Lenses) connected to the implanted optic fiber by a zirconia mating sleeve (Doric Lenses). Running wheel activity was recorded in 6 min bins using Clocklab software (Actimetrics; RRID: SCR_014309). After at least $3 \mathrm{~d}$ of acclimation to tethering, we began fiber photometry recordings using established methods (EbanRothschild et al., 2016). To control for motion artifacts, we excited GCaMP6s with its calcium-dependent excitation wavelength of $470 \mathrm{~nm}$ and at its calcium-independent isosbestic excitation wavelength of 405 $\mathrm{nm}$ (Lerner et al., 2015). Blue $470 \mathrm{~nm}$ and violet $405 \mathrm{~nm}$ LED lights (M470F3 and M405FP1, Thorlabs) were sinusoidally modulated at 211 and $531 \mathrm{~Hz}$, respectively, using a custom Matlab program (MathWorks; RRID:SCR_001622) and a multifunction data acquisition device (NI PCI-6110, National Instruments). The excitation lights passed through a fluorescence cube (FMC4, Doric Lenses) containing two separate excitation filters (450-490 and $405 \mathrm{~nm})$, reflected off a dichroic mirror and coupled into the tethered fiber-optic cable. The light intensity for each wavelength was set to $\sim 30 \mu \mathrm{W}$ at the termination of the fiber-optic cable. Sinusoidally modulated GCaMP6s fluorescence was collected through the same fiber-optic cable, passed through an emission filter (500-550 $\mathrm{nm}$ ), and focused through a patch cord onto a femtowatt photoreceiver (model 2151, Newport). The photoreceiver signal was then sent to two lock-in amplifiers (30 ms time constant; model SR830, Stanford Research Systems) that were synchronized to 211 or $531 \mathrm{~Hz}$ for demodulation. Voltage signals from the amplifiers were collected at $10 \mathrm{kHz}$ using a custom Matlab program and a multifunction data acquisition device and saved to disk as binary files. For spontaneous activity experiments, hourly 10 min recordings were obtained automatically using a custom Matlab program. For light-evoked activity experiments, hourly recordings were obtained similarly with the addition of $15 \mathrm{~s}$ of illumination from the chamber lights delivered at $2 \mathrm{~min}$ into the $10 \mathrm{~min}$ data acquisition period. Animals were excluded from analysis if both the calcium-dependent and calcium-independent signals simultaneously fluctuated by $\sim 100 \mathrm{mV}$ (an indicator that the fiber was positioned below the SCN), if they did not exhibit circadian locomotor activity or if the fiber or virus was off-target as determined by histology.

Fiber photometry data analysis. Data files were opened in Matlab and downsampled to $1 \mathrm{kHz}$ for further analysis as in the study by Zalocusky et al. (2016). To account for different photobleaching dynamics, extracted calcium-dependent $(470 \mathrm{~nm})$ and calcium-independent $(405 \mathrm{~nm})$ signals were individually fit with an exponential filter, and the fitted signals were subtracted from the raw signals. Signals were then bandpass filtered between 0.016 and $2 \mathrm{~Hz}$ (spontaneous recordings) or 0.003 and $2 \mathrm{~Hz}$ (evoked recordings) and fit to one another using a linear least-squares fit. The change in fluorescence over baseline fluorescence $(\Delta F / F)$ was calculated as (488 nm signal-fitted $405 \mathrm{~nm}$ signal)/(fitted $405 \mathrm{~nm}$ signal). Final values were adjusted so that a $\Delta F$ of 0 corresponded to the second percentile of the signal. $\Delta F / F$ values were converted to events by counting instances $>1 \mathrm{~s}$ when $\Delta F / F$ exceeded the median plus $2 \mathrm{SDs}$ of the trace or $1.5 \% \Delta F / F$, whichever was greater. We report the number of events per minute and also the integrated calcium values, as defined by integrating the $\Delta F / F$ values $>0 \%$ for $>10 \mathrm{~min}$. For light-evoked recordings, re- 
sponse amplitude was defined as the peak $\Delta F / F$ during 2 min following the start of the light pulse divided by the median $\Delta F / F$ during the $2 \mathrm{~min}$ preceding the light pulse, and response duration was defined as the time from the end of the light pulse until the signal returned to the median $\Delta F / F$ of the entire recording.

VIP sensor cell production. The cognate VIP receptor in the SCN, VPAC2R, is preferentially coupled to a $\mathrm{G} \alpha_{\mathrm{s}}$-adenylate cyclase-cAMP pathway (Langer, 2012). To generate reporter cells (Muller et al., 2014; Gizowski et al., 2016) that respond to VIP through a $\mathrm{G} \alpha_{\mathrm{q}}$-phospholipase C-calcium pathway (Offermanns and Simon, 1995; Zhu et al., 2008), HEK293 cells (American Type Culture Collection; RRID:CVCL_0045) were sequentially transfected with pcDNA3.1(+)-hVipr2 (neomycin/ kanamycin selection sequence replaced with puromycin sequence) and then pcDNA3.1(+)-hG $\alpha_{15(16)}$ plasmids (cDNA Resource Center). Sixteen microliters of FuGENE Transfection Reagent (Promega) and $1 \mu \mathrm{g}$ of plasmid DNA were diluted in Opti-MEM (Thermo Fisher Scientific) to a final volume of $250 \mu \mathrm{l}$. Transfection medium in $2 \mathrm{ml}$ of DMEM with $5 \%$ fetal bovine serum (FBS; Thermo Fisher Scientific) was added to HEK293 cells at $60-80 \%$ confluency and removed after 15-20 h. Transfected cells were maintained at $37^{\circ} \mathrm{C}$ and $5 \% \mathrm{CO}_{2}$ in $\mathrm{CO}_{2}$-buffered DMEM with $10 \%$ FBS and 1\% penicillin/streptomycin (Thermo Fisher Scientific) for $2 \mathrm{~d}$. On day 3 , the antibiotic was replaced with $0.4 \mu \mathrm{g} / \mathrm{ml}$ puromycin (Thermo Fisher Scientific). Cells were selected for $10 \mathrm{~d}$. Single-transfected and selected cells were then transfected with the second plasmid, as described. Double-transfected cells were selected with $550 \mu \mathrm{g} / \mathrm{ml} \mathrm{G418} \mathrm{sulfate}$ (Thermo Fisher Scientific) for $10 \mathrm{~d}$. Doses of puromycin and G418 were determined through a HEK293 kill curve using ranges of $0.38-0.44$ and $200-800 \mu \mathrm{g} / \mathrm{ml}$, respectively. Double-transfected and selected cells (HEK293 Vipr2+hG+) were kept in media with puromycin and G418 antibiotics until ready for reporter transfection and recording. To verify successful double transfection, cells were immunostained with the primary antibodies rabbit anti-VPAC2 (1:500; catalog \#ab28624, Abcam; RRID:AB_778889) and mouse anti-G $\alpha_{15}$ (1:50; catalog \#sc-393878, Santa Cruz Biotechnology; RRID:AB_2734138) and the secondary antibodies Alexa Fluor 488 donkey anti-rabbit and Alexa Fluor 594 donkey anti-mouse (1:500; catalog \#711-545-152 and \#715-585-150, Jackson ImmunoResearch; RRID:AB_2313584 and AB_2340854, respectively). Twenty-four hours before recording, $5 \times 10^{4}$ cells were plated on glassbottom dishes coated with a mixture of poly-D-lysine, laminin, and collagen (Sigma-Aldrich). Three to four hours after plating, we transfected cells with the fluorescent calcium reporter pGP-CMV-NES-jRCaMP1b (Addgene; Dana et al., 2016). Before recording, the media were changed to recording media containing DMEM supplemented with $100 \mathrm{U} / \mathrm{ml}$ penicillin, $100 \mu \mathrm{g} / \mathrm{ml}$ streptomycin, $10 \mathrm{~mm}$ HEPES, $0.35 \mathrm{~g} / \mathrm{L}$ NaHCO3, $4.5 \mathrm{~g} / \mathrm{L}$ D-glucose, $2 \%$ L-glutamine, and $1 \times$ B27 cell culture supplement (Thermo Fisher Scientific). To determine the responsivity and specificity of the reporter cells, $1 \mu \mathrm{l}$ of 1,10 , or $100 \mathrm{~nm}$ VIP (Bachem) or $100 \mathrm{~nm}$ gastrin-releasing peptide (GRP; Sigma-Aldrich) diluted in recording media was pipetted directly above the plated cells and imaged.

Organotypic SCN culture and in vitro VIP sensor recording. SCN slices were obtained using methods modified from the study by Abe et al. (2002). Mice were anesthetized with $\mathrm{CO}_{2}$ and decapitated. Brains were quickly removed and placed in cold oxygenated HBSS. Coronal sections $(250 \mu \mathrm{m})$ containing the SCN were obtained using a vibratome (catalog \#OTS-5000, Electron Microscopy Sciences). SCNs were dissected and cultured individually on cell culture membranes (catalog \#PICM0RG50, Millipore), which were then placed into a $35 \mathrm{~mm}$ Petri dish (Falcon) with $1 \mathrm{ml}$ of recording medium, sealed with vacuum grease, and incubated at $37^{\circ} \mathrm{C}$ overnight. The following day, culture membranes containing the SCN were transferred to dishes containing cultured VIP sensor cells. We extrapolated subjective time of day in vitro from the prior light cycle. For time-lapse recordings, dishes were placed on an inverted microscope (Eclipse TE2000-S, Nikon) within an incubation chamber (In Vivo Scientific) held at $25^{\circ} \mathrm{C}$. VIP sensor fluorescence was imaged with a $10 \times$ objective focused on the reporter cells, a TRITC filter cube (Chroma), and a digital EMCCD camera (iXon DU-897, Andor Technology), recorded automatically at $1 \mathrm{frame} / \mathrm{s}$ for $10 \mathrm{~min} / \mathrm{h}$ for $24 \mathrm{~h}$ using a custom $\mu$ Manager script (http://micro-manager.org; RRID:SCR_000415). Recordings were stopped after $24 \mathrm{~h}$ before reporter cells reached conflu- ence. For acute recordings, VIP sensor cells were prepared as above and kept at $25^{\circ} \mathrm{C}$ until they were imaged with SCN slices taken at either 11:00 A.M. to 1:00 P.M. [circadian time (CT)] 6 or 5:00 to 7:00 P.M. (CT 12) the previous day. We imaged VIP sensor fluorescence for 5-8 min using a TRITC filter cube and a digital CCD camera (QIClick, QImaging) at 1 frame/s with QCapture (QImaging) and CamStudio software. We then pipetted $1 \mu \mathrm{l}$ of 1 or $10 \mathrm{~nm}$ NMDA (Sigma-Aldrich) directly onto the SCN slice and recorded for an additional 8-10 min. In all experiments, dishes were excluded from analysis if the VIP sensors did not respond to exogenous VIP application.

VIP sensor analysis. Frames were extracted from movie files using Matlab and opened as TIFF stacks in ImageJ (http://imagej.nih.gov/ij; RRID: SCR_003070) for analysis. Recordings were bleach corrected using an exponential fit and background subtracted using a rolling ball algorithm to eliminate SCN autofluorescence. Regions of interest (ROIs) were selected using an SD projection and a diameter threshold of 5-30 pixels ${ }^{2}$. The mean pixel intensity values for each ROI calculated for each frame were then processed in Matlab by first dividing by the mean pixel value of the entire frame to generate a background-corrected pixel intensity value. The $\Delta F / F$ value for each ROI for a given frame $n$ was then calculated as (corrected pixel intensity value for frame $n-$ median pixel intensity values across all frames)/(median pixel intensity values across all frames). The resulting $\Delta F / F$ values were smoothed by a $5 \mathrm{~s}$ moving average filter. For recordings of spontaneous activity, as there was no prestimulus or poststimulus epoch, data were analyzed by integrating the single-cell $\Delta F / F$ over each hourly $10 \mathrm{~min}$ recording. This single-cell integrated fluorescence was summed and divided by the number of cells analyzed in that hour to account for reporter cell proliferation to produce an average integrated fluorescence per cell. For evoked responses, the maximum $\triangle F / F$ for each cell was calculated before and after NMDA stimulation.

In vivo VIP neuron inhibition. After recovery, mice were transferred to wheel-running cages and housed in DD in a light-tight, temperature- and humidity-controlled chamber with food and water provided ad libitum. After allowing the mice to run free for multiple days, we injected them with clozapine- $N$-oxide $(\mathrm{CNO} ; 1 \mathrm{mg} / \mathrm{kg}$, i.p.; Hello Bio) $30 \mathrm{~min}$ before activity onset (Grippo et al., 2017). Mice were returned to their cages and allowed to run free for multiple days and then were injected again with CNO at CT 11.5, 30 min before a 15 min light pulse [bright (ranging from $5 \times 10^{15}$ to $2 \times 10^{16}$ photons $/ \mathrm{s} / \mathrm{cm}^{2}$ throughout the cage $)$ or $\operatorname{dim}(\sim 4 \times$ $10{ }^{14}$ photons $/ \mathrm{s} / \mathrm{cm}^{2}$ ) light pulse], returned to their cages and allowed to free run for multiple days. Phase shifts were determined by using activity onset analysis in Clocklab, using at least $4 \mathrm{~d}$ of data per condition (baseline, after $\mathrm{CNO}$, and after $\mathrm{CNO}+$ light pulse). The day of drug administration was excluded from analysis. A regression line was fit through activity onsets and extrapolated before and after each condition; phase shift duration was determined by calculating the time difference in regression lines extrapolated to the days of drug administration (i.e., the time difference between the predicted and actual phase onsets). To determine light-evoked activation of VIP neurons, mice were injected with CNO at CT 11.5, received a 15 min bright-light pulse at CT 12, returned to DD, and perfused $1 \mathrm{~h}$ after the start of the light pulse, as described below.

Histology and image analysis. Mice were deeply anesthetized with isoflurane $(>5 \%)$ and transcardially perfused with PBS followed by $4 \%$ paraformaldehyde. Brains were extracted, postfixed overnight in $4 \%$ paraformaldehyde, and cryoprotected in 30\% sucrose. Coronal sections $(40 \mu \mathrm{m})$ containing the SCN were collected using a cryostat (Leica) and stored at $4^{\circ} \mathrm{C}$ in PBS. Immunostaining was performed as previously described (Grippo et al., 2017; Tso et al., 2017). The primary antibodies used were rabbit anti-mCherry (1:1000; catalog \#ab167453, Abcam; RRID:AB_2571870) and goat anti-c-Fos (1:1000; catalog \#sc52-G, Santa Cruz Biotechnology; RRID:AB_2629503). Secondary antibodies used were DyLight 594 donkey anti-rabbit (1:500; catalog \#SA5-10040, Thermo Fisher Scientific; RRID:AB_2556620), DyLight 488 donkey antigoat (1:500; catalog \#SA5-10086, Thermo Fisher Scientific; RRID: AB_2556666), and CF 647 donkey anti-goat (1:500; SAB4600175, SigmaAldrich; RRID:AB_2734139). The $2048 \times 2048$ pixel images of the SCN were acquired on a Nikon Al Confocal Microscope as a single $z$-stack 
a

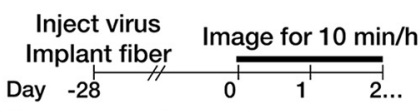

GCaMP6s or EGFP Fiber optic cannula

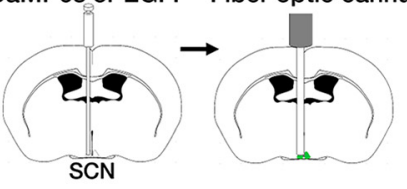

C

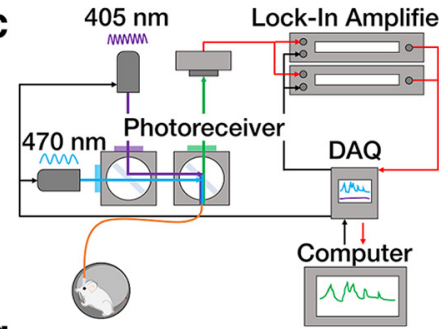

g

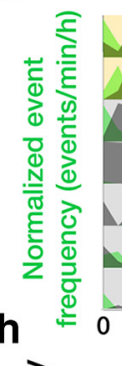

b

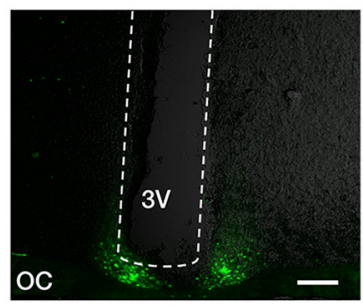

\section{d}

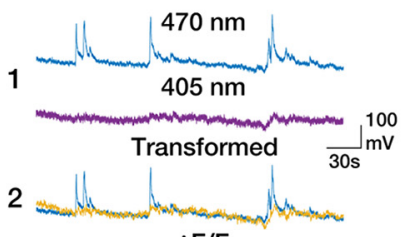

3

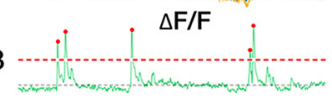

$12 \%$ e

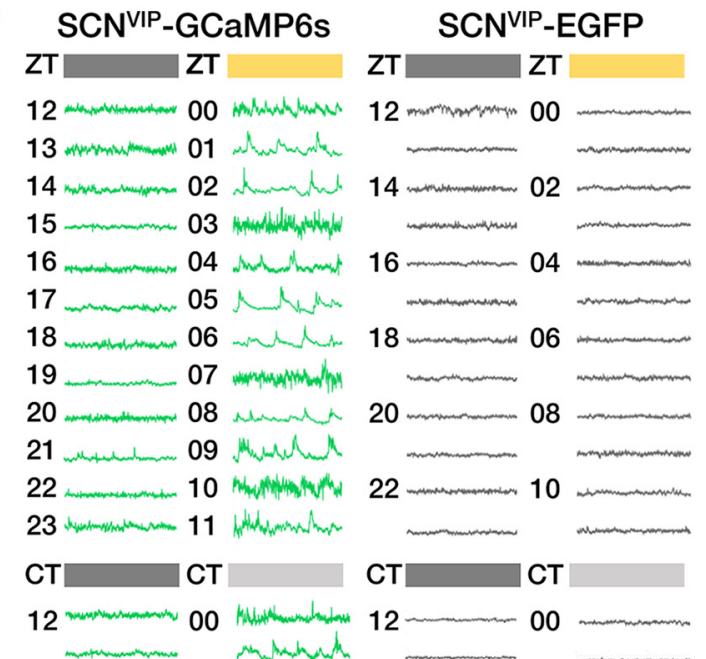

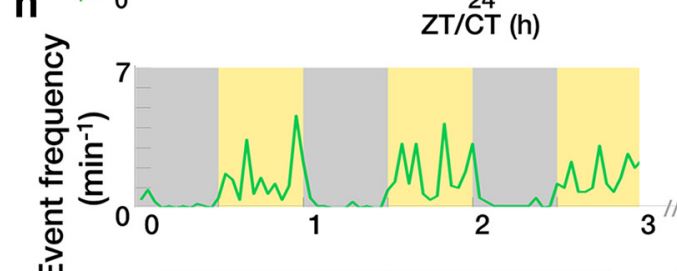
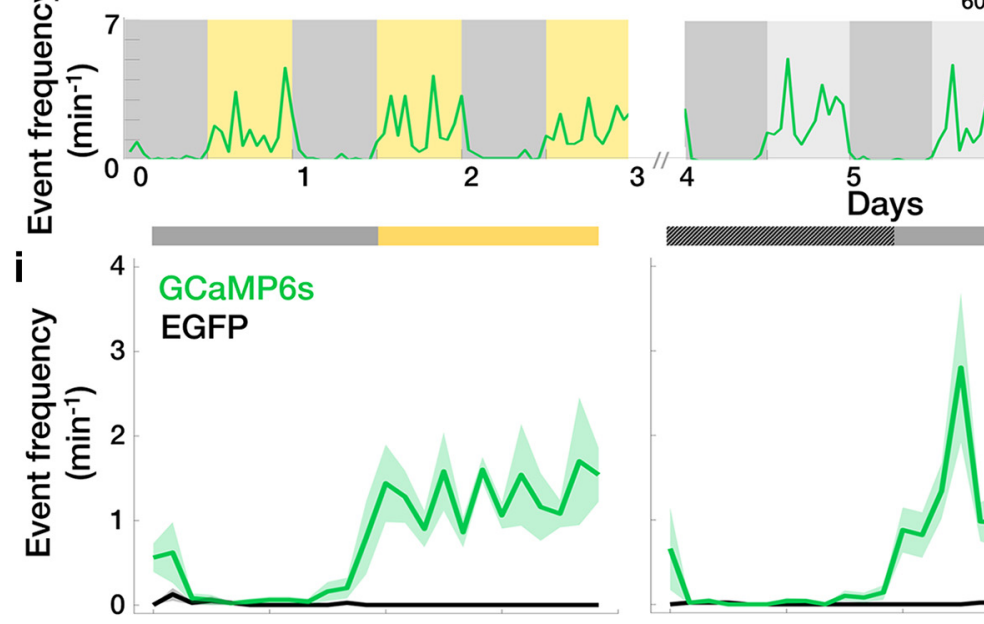

$$
14
$$$$
02
$$

14

02

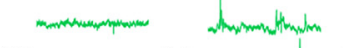

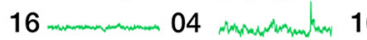

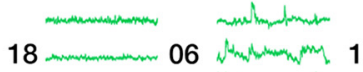

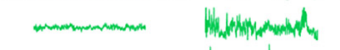

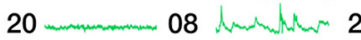

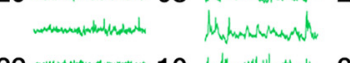

22 - 10 $60 \mathrm{~s}$
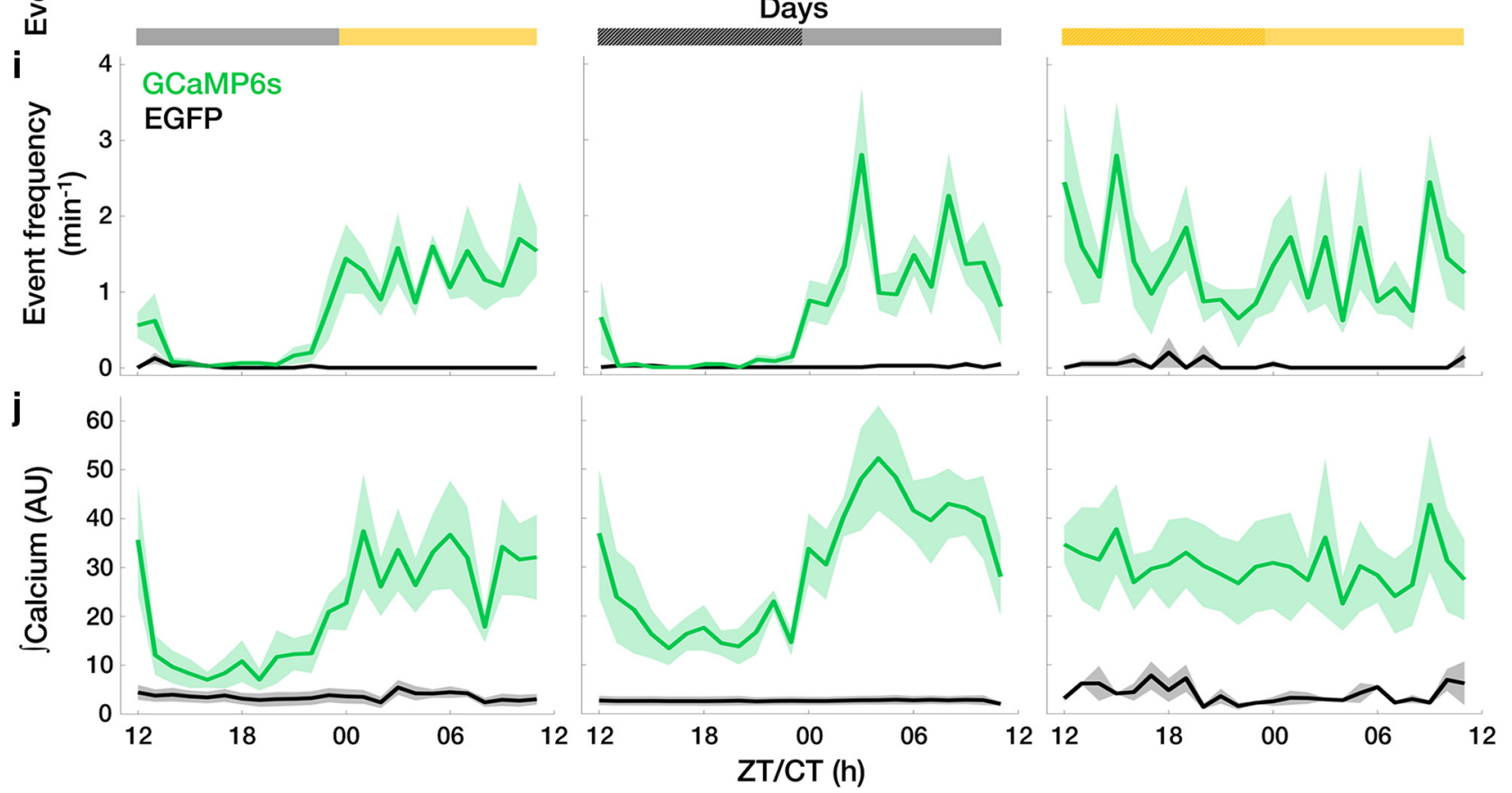

Figure 1. SCN VIP neurons exhibit daily rhythms in spontaneous calcium activity in vivo. $\boldsymbol{a}$, Fiber photometry experimental timeline and schematic. $\boldsymbol{b}$, Representative image of a fiber-optic cannula (white dashed lines) positioned above a GCaMP6s ${ }^{+}$SCN. OC, Optic chiasm; 3V, third ventricle. Scale bar, $200 \mu \mathrm{m}$. c, Schematic of the two-color excitation system used to measure calcium-evoked ( $470 \mathrm{~nm}$ ) or calcium-independent ( $405 \mathrm{~nm}$ ) fluorescence. $\boldsymbol{d}$, Illustration of calcium event detection. Blue, Raw $470 \mathrm{~nm}$ signal; purple, raw $405 \mathrm{~nm}$ signal; yellow, detrended $405 \mathrm{~nm}$ signal; green, $\Delta F / F$; dashed line, event threshold value; red circles, events. $\boldsymbol{e}, \boldsymbol{f}$, Hourly $\Delta F / F$ traces taken from VIP neurons in transgenic mice with (GCaMP6s) or without (EGFP) a fluorescent calcium reporter in a daily LD cycle (yellow = light phase) or DD (light gray = subjective day). $\boldsymbol{g}$, Double-plotted actogram of normalized event frequency per hour (green) and normalized locomotor activity counts per hour (black) recorded from an individual GCaMP6s ${ }^{+}$mouse housed in LD (gray and yellow shading) and DD (gray shading). A 10 min light pulse (yellow) (Figure legend continues.) 


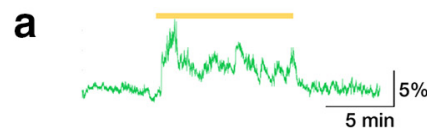

b

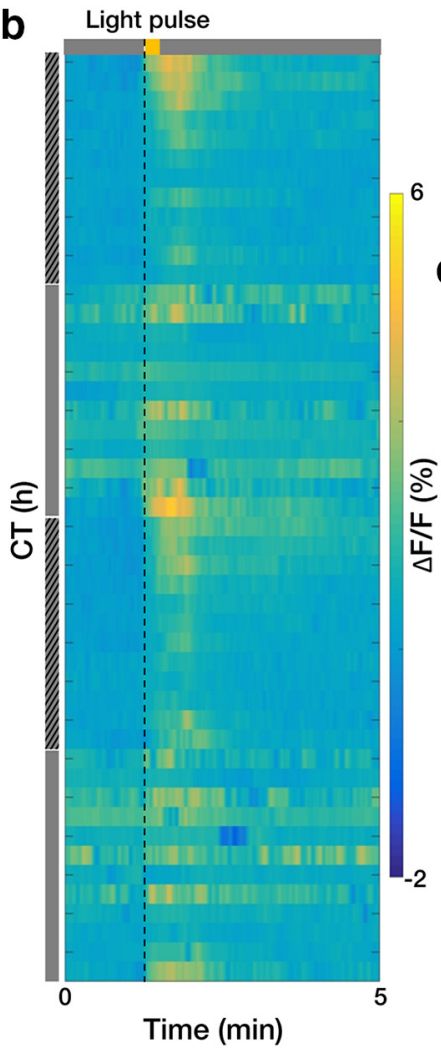

C

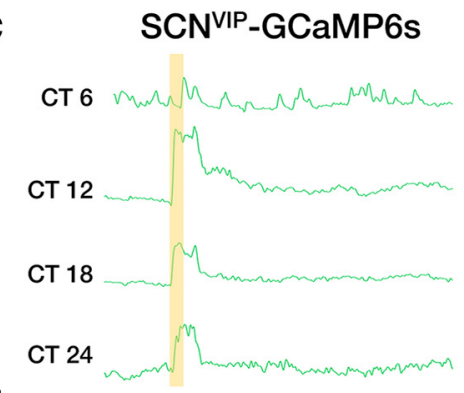

d
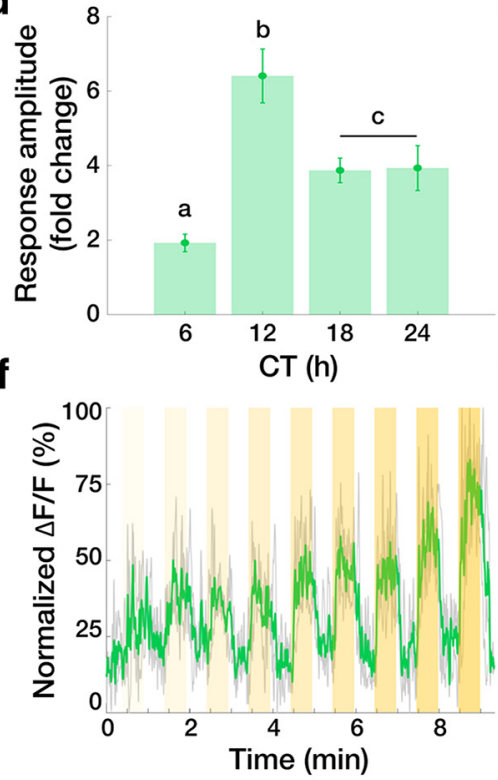
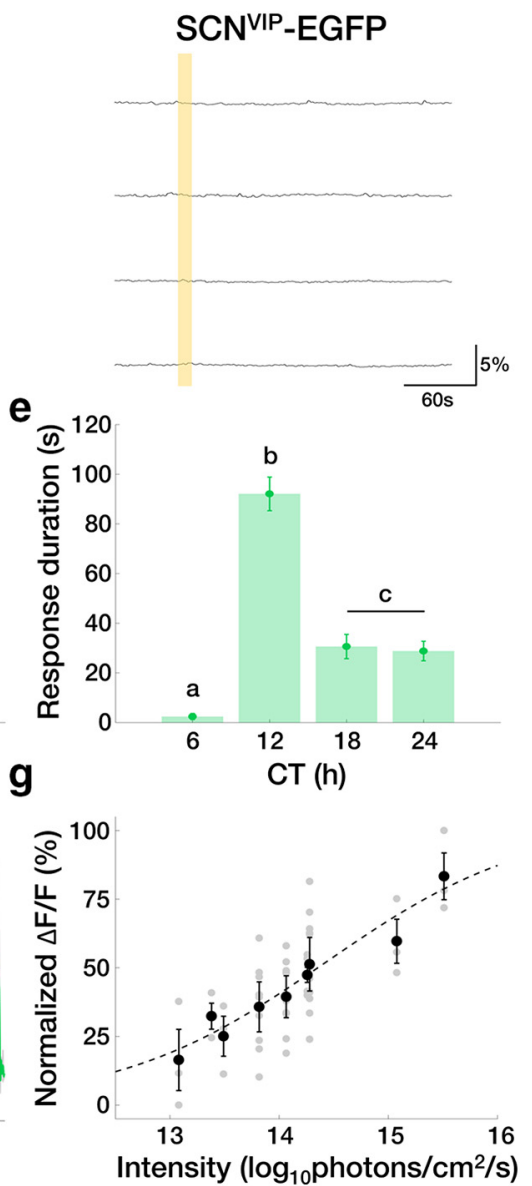

Figure 2. SCN VIP neurons exhibit daily rhythms in light-evoked calcium activity in vivo. $\boldsymbol{a}$, Representative $\Delta F / F$ trace in response to a 10 min light pulse given at $C T 12 . \boldsymbol{b}$, Representative heatmap depicting $\Delta F / F$ traces in response to a $15 \mathrm{~s} \mathrm{light} \mathrm{pulse} \mathrm{(dashed} \mathrm{line)} \mathrm{given} \mathrm{every} \mathrm{hour} \mathrm{for} 48 \mathrm{~h}$. Hatched gray bar, subjective night; gray bar, subjective day. $c$, Representative calcium responses to a $15 \mathrm{~s}$ light pulse presented to representative GCaMP6s and EGFP mice at different circadian times. $\boldsymbol{d}, \boldsymbol{e}$, The amplitude and duration of the light-evoked calcium response of VIP neurons at different CTs peaked around subjective dusk ( $n=4$ mice, 2 trials/CT; one-way repeated-measures ANOVA: $F_{(3,21)}=14.15, p<0.0001 ; F_{(3,21)}=67.08, p<0.0001$; with post hoc Tukey's MCT). $f$, Representative $\Delta F / F$ trace in response to 30 s pulses of increasing light intensity (yellow bars; shading indicates brighter light) given at $C T$ 12. Green line indicates the mean response of three repeated trials (gray) normalized within trial to the maximum $\Delta F / F$ response. $\boldsymbol{g}$, Maximum $\Delta F / F$ response to 30 s light pulses given at $\mathrm{CT} 12$ increased with light intensity. $n=3$ mice, 3-9 trials/light intensity. Dashed line depicts sigmoid fit, $r^{2}=0.4865$. Error bars depict the means \pm SEM; letters indicate statistically different groups.

(optical section thickness, $2 \mu \mathrm{m}$ ) using identical capture settings for each image, which was to be quantitatively compared. For quantitative c-Fos analysis, sections were $z$ projected by their average intensity using ImageJ software. Regions of interest were selected automatically in ImageJ using Shanbhag thresholding with identical settings for each section followed by particle analysis with size and circularity thresholds of $\geq 200$ pixels ${ }^{2}$ and $\geq 0.1$, respectively. Brightness and contrast settings were adjusted identically for sections depicted in representative images.

Statistics. Sample sizes were chosen to be sufficient for statistical analysis based upon similar techniques used in previous publications (EbanRothschild et al., 2016). Data analysis was performed blind to genotype or condition. There were no methods to randomize mice to experimental groups or to blind investigators to genotype or condition during the experiments. All statistical analyses including one-way ANOVA, twoway ANOVA, one-way repeated-measures ANOVA, two-way repeated-

(Figure legend continued.) was given at CT 0 on day 5. $\boldsymbol{h}$, Long-term recordings revealed reliable daily rhythms in the rate of VIP neuron calcium events from a representative $\mathrm{GCaMP6s}^{+}$mouse in LD and DD. $\boldsymbol{i}, \boldsymbol{j}$, The average daily profile of VIP neuron calcium event frequencies and integrated calcium levels depended on circadian time and the presence of light in LD, DD, or LL (light yellow = subjective day) in GCaMP6s (green; $n=5,5,4$ mice; JTK cycle, $p<0.001$ ), but not EGFP (black; $n=5,4,2 ;$ JTK cycle, $p>0.05$ ) mice. Light during subjective night in LL increased event frequency compared with DD or LD (two-way ANOVA: $F_{(2,330)}=$ $19.48, p<0.001$; with post hoc Tukey's MCT). Lines and shadings depict the mean \pm SEM. measures ANOVA, Student's $t$ test, Tukey's multiple-comparison test (MCT), and Sidak's MCT were performed in Matlab R2016a or Prism 7 (GraphPad; RRID:SCR_002798) with $\alpha$ defined as 0.05. Circadian rhythmicity was determined using cosinor analysis (Refinetti et al., 2007) in Matlab and independently using the JTK Cycle (Hughes et al., 2010) in R (RRID:SCR_001905). Shapiro-Wilk and Brown-Forsythe tests were used to test for normality and equal variances. Data are presented as the mean \pm SEM.

\section{Results}

\section{SCN VIP neurons exhibit daily rhythms in spontaneous} calcium activity in vivo

To determine the circadian regulation of SCN VIP neuron activity over multiple days, we used long-term in vivo fiber photometry to record hourly spontaneous calcium activity from the SCNs of freely moving mice (Fig. $1 a-d$ ). We injected a Cre-dependent AAV encoding the fluorescent calcium sensor GCaMP6s (AAV9CAG-Flex-GCaMP6s) or a control fluorophore (AAV9-CAGFlex-EGFP) into the SCNs of VIP-IRES-Cre knock-in mice. We found daily rhythms in intracellular calcium levels and event frequency that persisted for as many days as we recorded, peaking during the daily minimum of locomotor activity in an LD cycle or in DD (Fig. 1e-j). The amplitude of the rhythm (LD day, $1.31 \pm$ 0.38 events/min; LD night, $0.09 \pm 0.15$ events/min; DD subjec- 
a

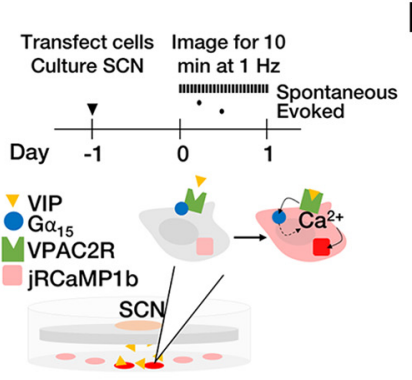

b

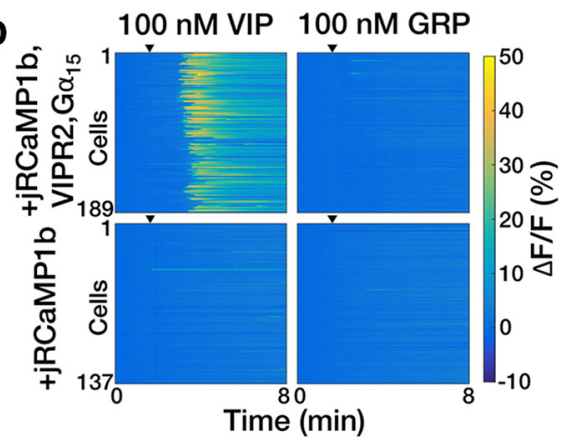

e d

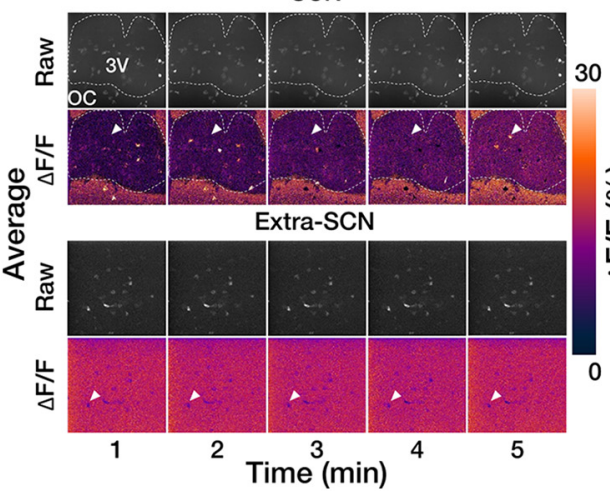

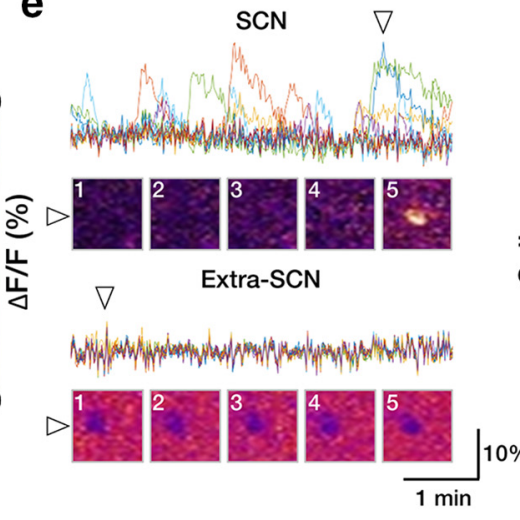

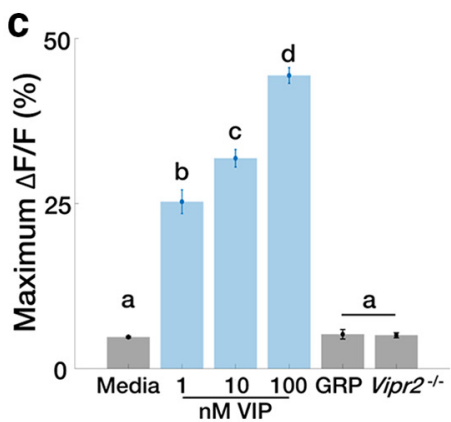

f

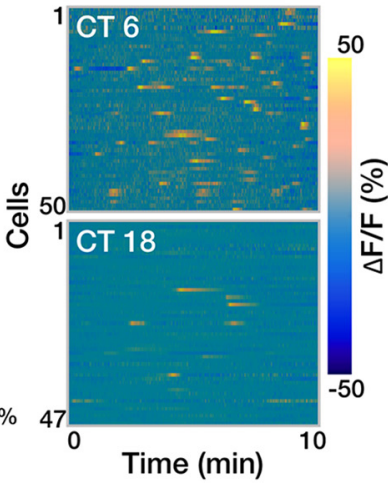

Figure 3. VIP sensor cells reliably detect VIP and reveal day-night differences in acute VIP release from the SCN. $\boldsymbol{a}$, Experimental outline and VIP sensor schematic. $\boldsymbol{b}$, jRCaMP1b calcium fluorescence in VIP reporter cells stably transfected with $G \alpha_{15}$ and VPAC2R increases in the presence of VIP, but not of GRP ( $n=189,137$ cells). c, VIP sensors exhibit a dose-dependent response to VIP concentration but do not respond to GRP or in the absence of VPAC2R ( $n=>500$ cells, 4 wells/group; one-way ANOVA: $F_{(5,18)}=242.2, p<0.0001 ;$ with post hoc Tukey's MCT. Error bars depict the mean \pm SEM; letters indicate statistically different groups. $\boldsymbol{d}$, Representative 1 min binned average raw pixel intensity and average $\Delta F / F$ images of VIP sensors cultured underneath an acute SCN slice (top) or in the same dish but away from the SCN (bottom). White dashed outline delineates the boundary of the SCN. 3V, Third ventricle; OC, optic chiasm. $e, \Delta F / F$ traces of the cells depicted in $\boldsymbol{d}$. Colors represent individual reporter cells; triangles designate cells indicated by white arrows in $\boldsymbol{d}$.f, Representative heatmaps of $\Delta F / F$ responses from VIP sensors cultured under acute $S C N$ slices explanted during the subjective day or night.

tive day, $1.34 \pm 0.48$ events/min; LD subjective night, $0.09 \pm 0.15$ events/min) was greatly disrupted in LL (day, $1.34 \pm 0.53$ events/ min; night $=1.41 \pm 0.58$ events/min; Fig. $1 i, j)$. These results suggest that SCN VIP neurons exhibit in vivo daily rhythms in spontaneous calcium activity.

\section{SCN VIP neurons exhibit daily rhythms in light-evoked calcium activity in vivo}

We next tested how SCN VIP neurons responded to light around subjective dusk when light is known to delay daily rhythms in behavior. We found that a $10 \mathrm{~min}$ light pulse reliably increased intracellular calcium (Fig. 2a). We therefore tested the effects of $15 \mathrm{~s}$ light pulses at different times of day and found that calcium responses exceeded baseline at CTs 12,18 , or 24 , but not during the middle of the subjective day (CT 6; Fig. 2b,c). These responses lasted multiple tens of seconds after the cessation of the light pulse, with daily peaks in amplitude and duration occurring at approximately CT 12 (Fig. 2d,e) and increased in amplitude with increasing light intensity (Fig. $2 f, g$ ). These results suggest that SCN VIP neurons exhibit in vivo daily rhythms in light-evoked calcium activity and can encode light intensity in a manner consistent with light-induced circadian phase shifts (Nelson and Takahashi, 1991).

\section{SCN slices exhibit daily rhythms in spontaneous and evoked} VIP release

To determine how SCN VIP neuron calcium activity correlates with the release of VIP, we engineered HEK293 reporter cells to selectively fluoresce in response to VIP (Fig. 3a). These cells reported VIP concentration in a dose-dependent manner (Fig. $3 b, c)$ and fluoresced when cultured under acute SCN slices, but not when in the same dish remote from the SCN (Fig. 3d,e). VIP sensor cells exhibited more spontaneous calcium activity when placed under acute wild-type SCN slices during the subjective day than during the subjective night (Fig. $3 f$ ). Spontaneous calcium activity was circadian when recorded continuously under cultured wild-type SCN slices, but was arrhythmic and low amplitude when recorded under Vip $^{-/-}$slices (Fig. $4 a-c$ ). Adding 1 or $10 \mathrm{~mm}$ NMDA to acute wild-type SCN slices at CT 12 to mimic light input (Ding et al., 1994; Mintz et al., 1999) also increased calcium activity in VIP sensors (Fig. $4 d, e$ ). Consistent with the inability of daytime light to shift the SCN, adding $1 \mathrm{mM}$ NMDA to the SCN at CT 6 did not change VIP sensor fluorescence. Importantly, adding NMDA to reporter cells alone or to a $\mathrm{Vip}^{-/-} \mathrm{SCN}$ slice at CT 12 did not change reporter cell fluorescence. Intriguingly, $10 \mathrm{~mm}$ NMDA during the subjective day reduced VIP sensor fluorescence (which could be restored by adding VIP). These results collectively suggest that there are daily rhythms in spontaneous and NMDA-evoked VIP release from the SCN, consistent with a role for VIP in mediating circadian-, light-, and NMDA-induced shifts of the SCN and behavior.

SCN VIP neuron activity is necessary for normal light-induced phase shifts

Finally, to determine the contribution of SCN VIP neurons to the encoding of light that shifts daily rhythms, we used chemogenet- 
a
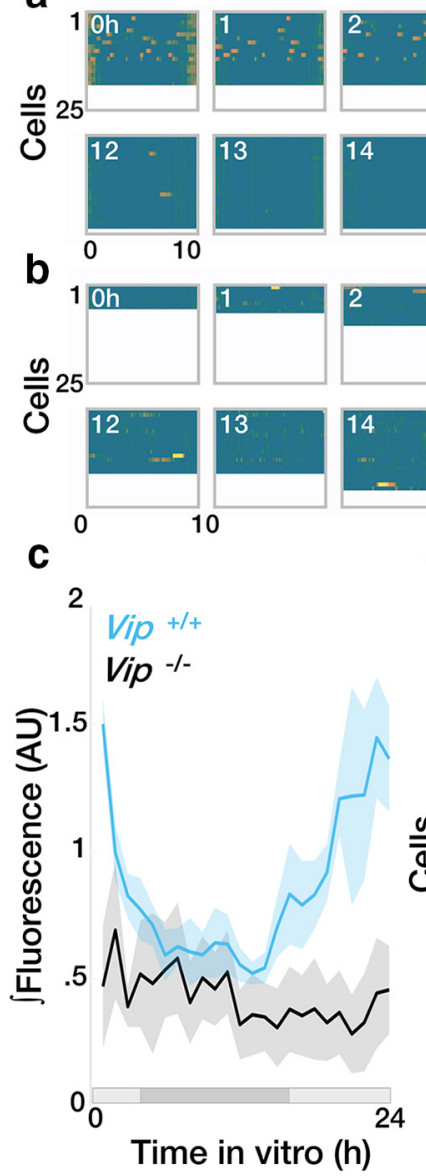
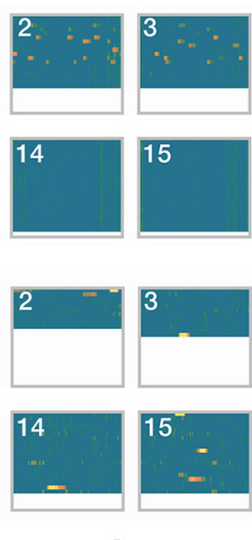

d
Vip $+1+$
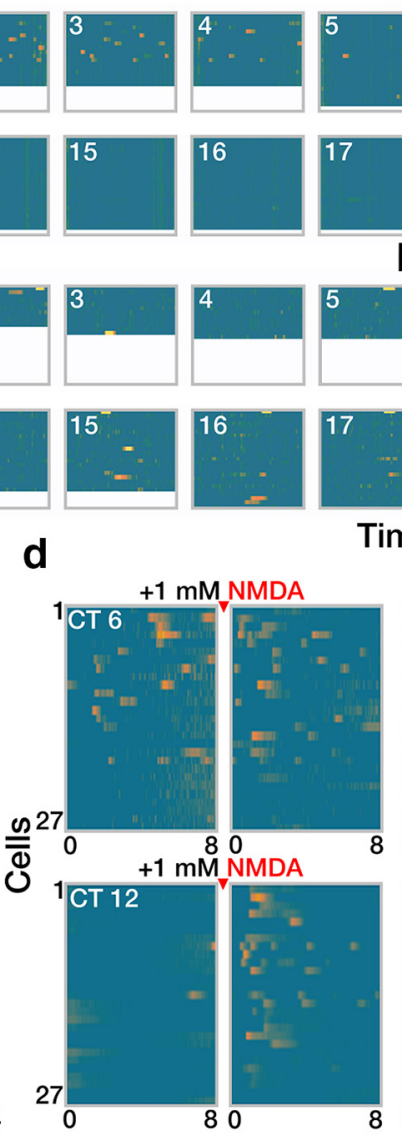

Time (min)
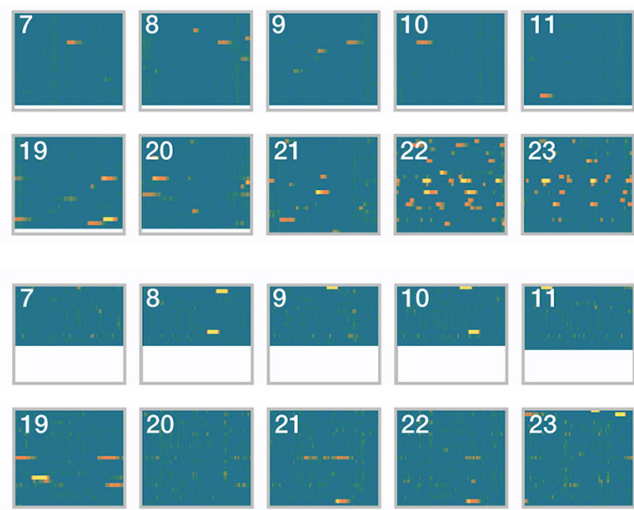

Vip $\%$

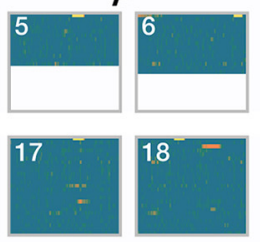

Time (min)
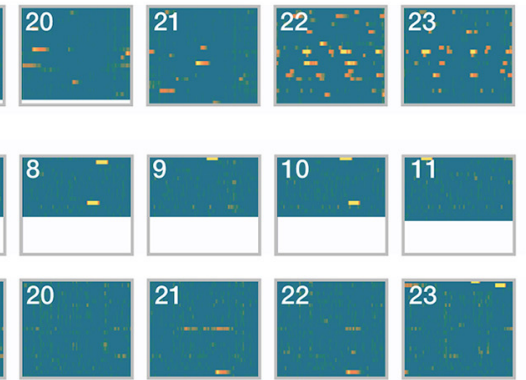
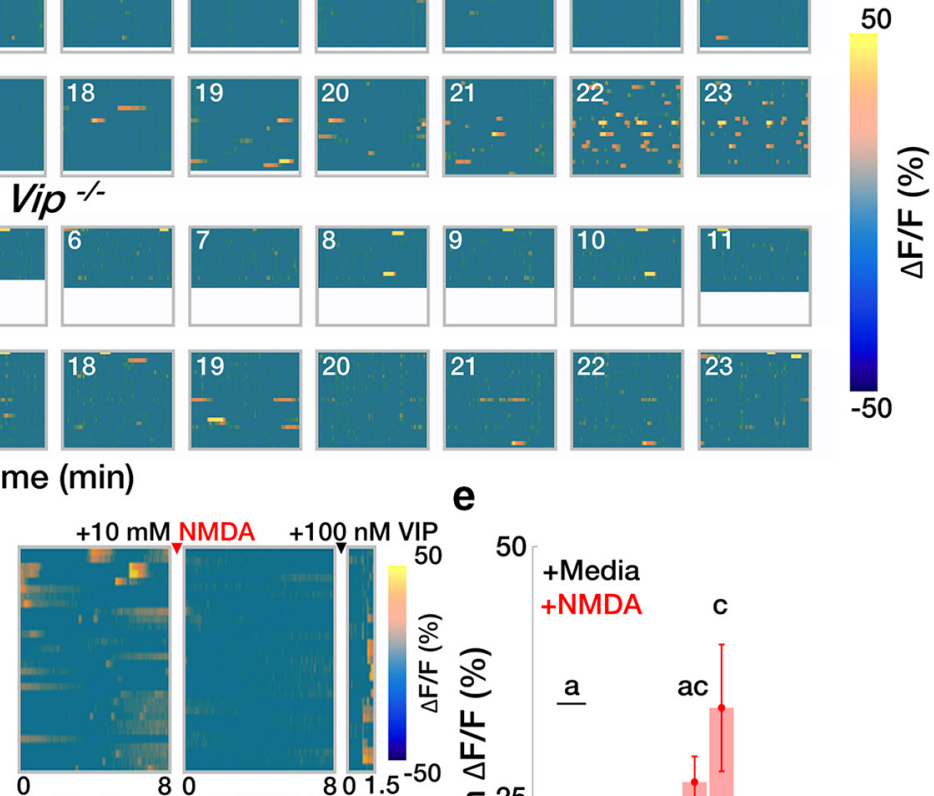

e

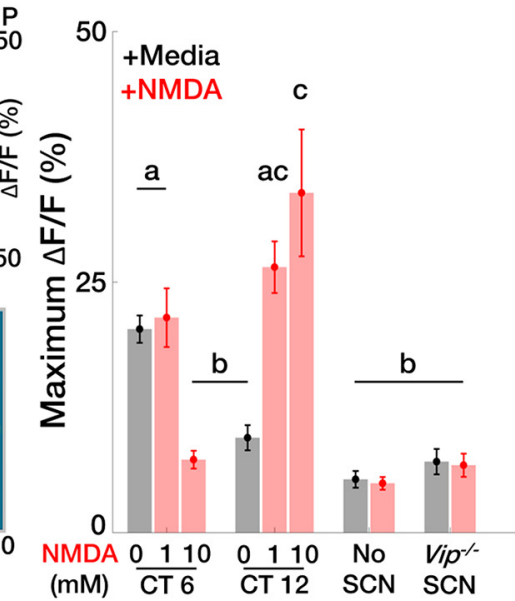

Figure 4. SCN slices exhibit daily rhythms in spontaneous and evoked VIP release. $\boldsymbol{a}, \boldsymbol{b}$, Representative hourly $\Delta$ F/F heatmaps showing the daily rhythm in average calcium responses integrated $>10$ min from individual reporter cells cultured under an organotypic wild-type or Vip ${ }^{-1-}$ SCN slice. $c$, Spontaneous VIP release varies with circadian time in wild-type $\left(V i p{ }^{+/+} ; n=5\right.$ slices; JTK cycle, $p<0.001)$, but not Vip ${ }^{-/-}(n=5$ slices, JTK cycle, $p>0.05)$, SCN slices. Shaded bar depicts the extrapolated subjective day (light gray) and night (dark gray). $\boldsymbol{d}, \boldsymbol{e}$, Heatmaps and summary plots of $\Delta$ F/Fresponses to $1 \mu$ l of 1 or 10 mm NMDA applied to acute $S C N$ slices cultured over VIP sensors at CT 6 or 12 ( $n=>100$ cells, 4 dishes $/$ group; two-way ANOVA, $F_{(9,36)}=17.29, p<0.0001$ with post hoc Tukey's MCT). Error bars depict the mean \pm SEM; letters indicate statistically different groups.

ics to acutely silence these neurons in freely behaving mice. We recorded circadian locomotor behavior from VIP-IRES-Cre mice injected with a SCN-targeted, Cre-dependent AAV encoding an engineered inhibitory $\mathrm{G}_{\mathrm{i}}$-coupled receptor (AAV8-hSyn-DIOhM4Di) or a control fluorophore (AAV9-CAG-Flex-EGFP; Fig. $5 a)$. We then silenced VIP neurons around the daily time of locomotor onset (CT 12), when in vivo VIP neuron calcium activity is decreasing and maximally augmentable by light exposure. We found that intraperitoneal injections of the hM4Di-specific ligand $\mathrm{CNO}$ at CT 11.5 attenuated, but did not fully block light induction of c-FOS, an indicator of neuronal activation, in the SCN (Fig. $5 b, c)$. CNO alone did not shift daily rhythms in locomotor activity in experimental or control mice (Fig. $5 d$ ), indicating that VIP neuron activity is not required at CT 12 for circadian rhythms to progress. Strikingly similar to its effects on photic induction of c-FOS, injection of CNO $30 \mathrm{~min}$ before a $15 \mathrm{~min}$ light pulse at CT 12 greatly attenuated the resulting phase delay from $2.10 \pm 0.21$ to $0.88 \pm 0.07 \mathrm{~h}$ compared with control animals (Fig. $5 d, e$ ). Finally, $\mathrm{CNO}$ also reduced phase delays of circadian behavior after light pulses that were $10 \times$ dimmer $(0.39 \pm 0.04 \mathrm{~h}$; compared with shifts of CNO-treated control mice, $0.91 \pm$ $0.04 \mathrm{~h}$; Fig. $5 f, g$ ). These results suggest that the depolarization of SCN VIP neurons is necessary for normal light-induced phase shifts.

\section{Discussion}

Together, these experiments demonstrate that SCN VIP neurons exhibit circadian rhythms in both spontaneous and light-evoked neuronal activity in vivo and in circadian and NMDA-evoked VIP release in vitro. Previous studies have reported circadian rhythms in basal calcium levels of VIP neurons in the isolated SCN in vitro (Enoki et al., 2017) and, recently, in vivo (Mei et al., 2018), but have differed on whether their firing rate is circadian (Webb et al., 2009; Fan et al., 2015; Hermanstyne et al., 2016). Here we provide the first evidence of the circadian regulation of calcium spikes in SCN VIP neurons, which likely relate to neuronal action potentials (Chen et al., 2013; Gunaydin et al., 2014). The regulation of these fast calcium events may be separable from the regulation of basal calcium levels under certain conditions (Ikeda et al., 2003; Enoki et al., 2012). Our results are consistent with light- and circadian-evoked VIP release from the SCN (Shinohara et al., 1995, 1999) which has been not been detectable in vivo (Francl et al., 2010). Similarly, our results suggest that physiological levels of NMDA induce VIP release by elevating neuronal activity at times of day when neuronal activity is low but not when neuronal activity is already high, which is consistent with a maximal effect of NMDA application on SCN phase shifts (Ding et al., 1994) and on SCN calcium transients (Colwell, 2001) occurring during the 


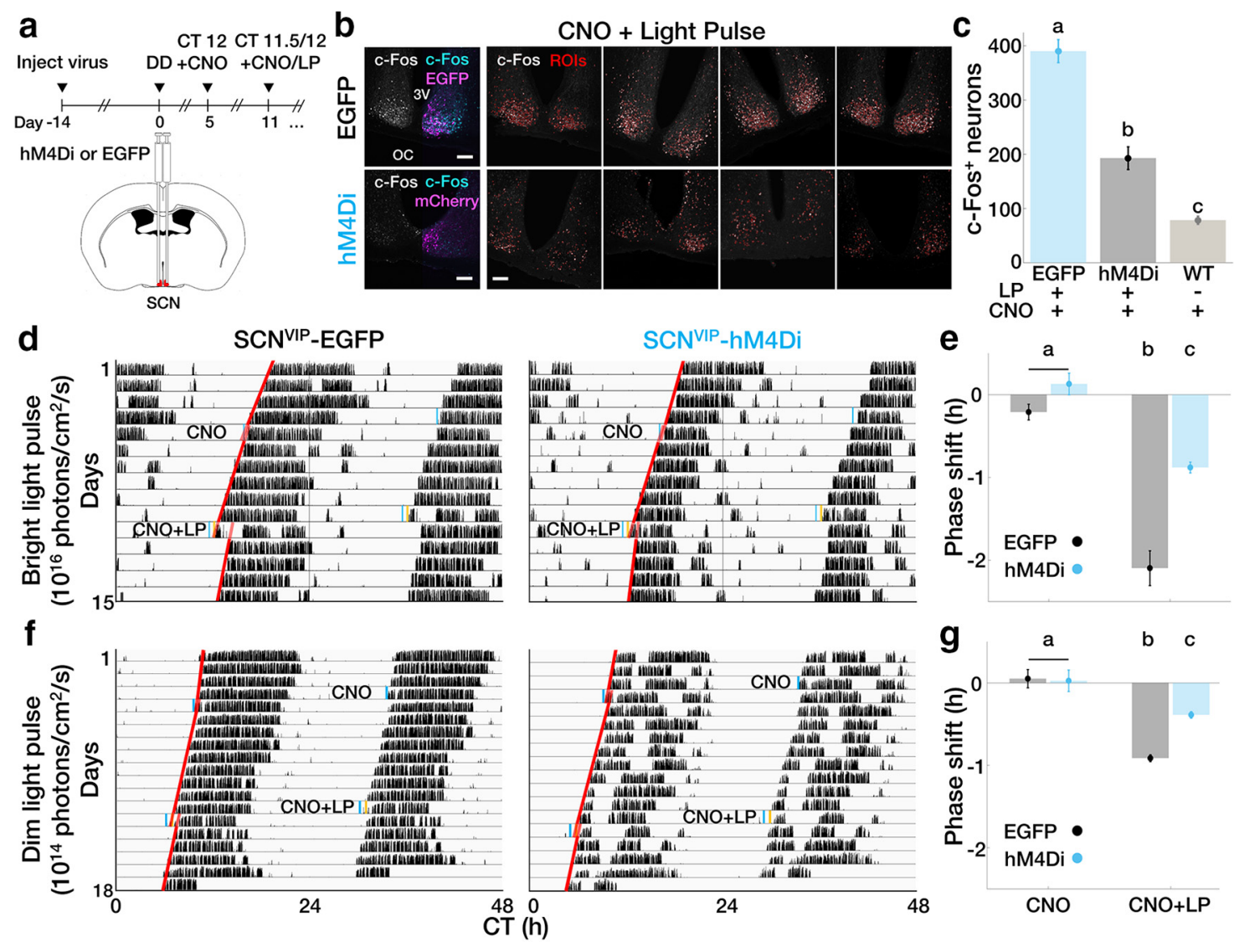

Figure 5. SCN VIP neuron activity is necessary for normal light-induced phase shifts. $\boldsymbol{a}$, Experimental outline and DREADD (designer receptors exclusively activated by designer drugs) schematic. $\boldsymbol{b}$, Left, Representative confocal images of a SCN slice taken from an EGFP- or hM4Di-expressing mouse $1 \mathrm{~h}$ after CNO and a 15 min light pulse. Grayscale shows c-Fos expression alone, and colored images show c-Fos (cyan) and EGFP or hM4Di-mCherry (magenta) coexpression. Right, SCN from individual EGFP and hM4Di mice ( $n=4 /$ group) taken $1 \mathrm{~h}$ after CNO administration plus a 15 min light pulse. c-Fos is depicted in grayscale; ROIs for automated cell counting were determined by Shanbhag auto-thresholding and are depicted as red outlines. 3V, Third ventricle; $0 \mathrm{C}$, optic chiasm. Scale bar, $100 \mu \mathrm{m}$. c, VIP neuron inhibition attenuated light-induced c-Fos expression $\left(n=4\right.$ mice/group; one-way ANOVA: $F_{(2,9)}=78.72, p<0.0001$, with post hoc Tukey's MCT). $\boldsymbol{d}$, Representative double-plotted actograms from transgenic mice free-running in DD without (EGFP) or with (hM4Di) SCN VIP neurons expressing an engineered inhibitory $\mathrm{G}_{\mathrm{i}}$-coupled receptor. Mice were given $1 \mathrm{mg} / \mathrm{kg}$ CNO alone or CNO plus a 15 min bright light pulse (LP) at CT 12. Blue, Time of CNO administration; yellow, 15 min bright light pulse; red, activity onset lines of best fit. e, CNO attenuated phase delays in response to a light pulse in hM4Di-expressing mice ( $n=4$ mice/group; two-way repeated-measures ANOVA: $F_{(1,6)}=28.97, p=0.0017$; with post hoc Sidak's MCT). $\boldsymbol{f}$, Representative double-plotted actograms from transgenic mice free-running in DD without (EGFP) or with (hM4Di) SCN VIP neurons expressing an inhibitory DREADD. Mice were given $1 \mathrm{mg} / \mathrm{kg}$ CNO alone or CNO plus a 15 min dim light pulse at CT 12. Blue, Time of CNO administration; yellow, 15 min dim light pulse; red, activity onset lines of best fit. $g$, CN0 attenuates phase delays in response to a dim light pulse in DREADD-expressing mice. $n=4$ mice/group; two-way repeated-measures ANOVA: $F_{(1,6)}=9.632, p=0.0210$; with post hoc Sidak's MCT. Error bars depict the mean \pm SEM, and letters indicate statistically different groups.

subjective night. High concentrations of NMDA, however, likely reduce VIP release during the subjective day by reducing elevated VIP neuron firing through depolarization block (Meijer et al., 1993).

Intriguingly, we also find that the in vivo circadian activity of VIP neurons rapidly becomes high and arrhythmic after acute exposure to constant light. This is consistent with results showing that chronic exposure to constant light increases levels of VIP (An et al., 2012) and disrupts the day-night difference in basal calcium levels in an in vitro SCN preparation (Colwell, 2000), but at apparent odds with the sustained circadian locomotor activity for multiple days in LL. We therefore postulate that aberrant lighting can elevate activity in SCN VIP neurons (some of which project to extra-SCN brain regions; Abrahamson and Moore, 2001) without immediate effects on circadian behavior, but with potential effects on behaviors such as mood (LeGates et al., 2012).

We found that silencing SCN VIP neurons attenuate, but do not block, light-induced shifts in circadian behavior. Although nocturnal light upregulates the markers of activation in VIP neu- rons (Romijn et al., 1996; Kuhlman et al., 2003), our results indicate that all photic signaling does not pass through VIP neurons to entrain rhythms in the SCN and behavior. This is surprising because shifts following optogenetic stimulation of most SCN neurons in vitro can be blocked with VIP receptor antagonists (Jones et al., 2015), and blocking the acute induction of the core clock gene Per1, which is preferentially induced in VIP neurons in response to a light pulse (Kuhlman et al., 2003), greatly attenuates light-induced behavioral phase shifts in vivo (Akiyama et al., 1999; Tischkau et al., 2003). Our results are, however, consistent with the observation that Vip-deficient mice can still synchronize to a light cycle (although with an $8 \mathrm{~h}$ advanced-phase angle of entrainment; Colwell et al., 2003), and that phase response curves to VIP and light differ in their shape (for review, see An et al., 2011). It is possible that genetic deletion of VIP early in development allows for compensation and that our chemogenetic manipulations did not fully silence all VIP neurons. However, because retinal ganglion cells make contacts on numerous cell types throughout the SCN (Fernandez et al., 2016) and light induces c-FOS broadly in the SCN (Castel et al., 1997), we posit that 
VIP neurons are a major, but not a unique, modulator of light entrainment of the SCN and behavior.

Interestingly, we found higher and longer light-induced VIP neuron calcium responses at subjective dusk compared with spontaneous VIP neuron calcium levels at any time, suggesting that light during the subjective night causes an increase in VIP neuronal activity, and, consequently, VIP release, that is above the normal daytime spontaneous activity levels occurring in these neurons. Because our results indicate that light activation of retinal afferents produces about half of the normal phase shift to SCN cells when SCN VIP neurons are silenced, we propose that light at night activates VIP and non-VIP SCN neurons. We predict that VIP released by VIP neurons enhances the non-VIP neuron response to light consistent with the antagonism or deletion of Vip signaling attenuating light induction of Perl and c-FOS in both the VIP-enriched ventral SCN and VIP-deficient dorsal SCN (Vosko et al., 2015). Based on the in vitro phaseresponse curve to VIP (An et al., 2011) and on our observations that these neurons maximally respond to light at dusk, this VIP neuron-mediated phase shifting likely predominantly involves phase delays. Thus, we conclude that SCN VIP neurons show daily rhythms in spontaneous neuronal activity with peak VIP release around mid-day, and that light at night augments their relatively low activity and VIP release to amplify shifts of the daily rhythm in the SCN and behavior.

\section{References}

Abe M, Herzog ED, Yamazaki S, Straume M, Tei H, Sakaki Y, Menaker M, Block GD (2002) Circadian rhythms in isolated brain regions. J Neurosci 22:350-356. CrossRef Medline

Abrahamson EE, Moore RY (2001) Suprachiasmatic nucleus in the mouse: retinal innervation, intrinsic organization and efferent projections. Brain Res 916:172-191. CrossRef Medline

Akiyama M, Kouzu Y, Takahashi S, Wakamatsu H, Moriya T, Maetani M, Watanabe S, Tei H, Sakaki Y, Shibata S (1999) Inhibition of light- or glutamate-induced mPer1 expression represses the phase shifts into the mouse circadian locomotor and suprachiasmatic firing rhythms. J Neurosci 19:1115-1121. CrossRef Medline

An S, Irwin RP, Allen CN, Tsai C, Herzog ED (2011) Vasoactive intestinal polypeptide requires parallel changes in adenylate cyclase and phospholipase C to entrain circadian rhythms to a predictable phase. J Neurophysiol 105:2289-2296. CrossRef Medline

An S, Tsai C, Ronecker J, Bayly A, Herzog ED (2012) Spatiotemporal distribution of vasoactive intestinal polypeptide receptor 2 in mouse suprachiasmatic nucleus. J Comp Neurol 520:2730-2741. CrossRef Medline

Atkins N Jr, Mitchell JW, Romanova EV, Morgan DJ, Cominski TP, Ecker JL, Pintar JE, Sweedler JV, Gillette MU (2010) Circadian integration of glutamatergic signals by little SAAS in novel suprachiasmatic circuits. PLoS One 5:e12612. CrossRef Medline

Aton SJ, Colwell CS, Harmar AJ, Waschek J, Herzog ED (2005) Vasoactive intestinal polypeptide mediates circadian rhythmicity and synchrony in mammalian clock neurons. Nat Neurosci 8:476-483. CrossRef Medline

Castel M, Belenky M, Cohen S, Wagner S, Schwartz WJ (1997) Lightinduced $c$-fos expression in the mouse suprachiasmatic nucleus: immunoelectron microscopy reveals co-localization in multiple cell types. Eur J Neurosci 9:1950-1960. CrossRef Medline

Chang AM, Aeschbach D, Duffy JF, Czeisler CA (2015) Evening use of lightemitting eReaders negatively affects sleep, circadian timing, and nextmorning alertness. Proc Natl Acad Sci U S A 112:1232-1237. CrossRef Medline

Chen TW, Wardill TJ, Sun Y, Pulver SR, Renninger SL, Baohan A, Schreiter ER, Kerr RA, Orger MB, Jayaraman V, Looger LL, Svoboda K, Kim DS (2013) Ultrasensitive fluorescent proteins for imaging neuronal activity. Nature 499:295-300. CrossRef Medline

Colwell CS (2000) Circadian modulation of calcium levels in cells in the suprachiasmatic nucleus. Eur J Neurosci 12:571-576. CrossRef Medline

Colwell CS (2001) NMDA-evoked calcium transients and currents in the suprachiasmatic nucleus: gating by the circadian system. Eur J Neurosci 13:1420-1428. CrossRef Medline
Colwell CS, Michel S, Itri J, Rodriguez W, Tam J, Lelievre V, Hu Z, Liu X, Waschek JA (2003) Disrupted circadian rhythms in VIP- and PHIdeficient mice. Am J Physiol Regul Integr Comp Physiol 285:R939-R949. CrossRef Medline

Dana H, Mohar B, Sun Y, Narayan S, Gordus A, Hasseman JP, Tsegaye G, Holt GT, Hu A, Walpita D, Patel R, Macklin JJ, Bargmann CI, Ahrens MB, Schreiter ER, Jayaraman V, Looger LL, Svoboda K, Kim DS (2016) Sensitive red protein calcium indicators for imaging neural activity. Elife 5:124. CrossRef Medline

Ding JM, Chen D, Weber ET, Faiman LE, Rea MA, Gillette MU (1994) Resetting the biological clock: mediation of nocturnal circadian shifts by glutamate and NO. Science 266:1713-1717. Medline

Eban-Rothschild A, Rothschild G, Giardino WJ, Jones JR, de Lecea L (2016) VTA dopaminergic neurons regulate ethologically relevant sleep-wake behaviors. Nat Neurosci 19:1356-1366. CrossRef Medline

Enoki R, Kuroda S, Ono D, Hasan MT, Ueda T, Honma S, Honma K (2012) Topological specificity and hierarchical network of the circadian calcium rhythm in the suprachiasmatic nucleus. Proc Natl Acad Sci U S A 109: 21498-21503. CrossRef Medline

Enoki R, Oda Y, Mieda M, Ono D, Honma S, Honma KI (2017) Synchronous circadian voltage rhythms with asynchronous calcium rhythms in the suprachiasmatic nucleus. Proc Natl Acad Sci U S A 114:E2476-E2485. CrossRef Medline

Fan J, Zeng H, Olson DP, Huber KM, Gibson JR, Takahashi JS (2015) Vasoactive intestinal polypeptide (VIP)-expressing neurons in the suprachiasmatic nucleus provide sparse GABAergic outputs to local neurons with circadian regulation occurring distal to the opening of postsynaptic GABA $A_{A}$ ionotropic receptors. J Neurosci 35:1905-1920. CrossRef Medline

Fernandez DC, Chang YT, Hattar S, Chen SK (2016) Architecture of retinal projections to the central circadian pacemaker. Proc Natl Acad Sci U S A 113:6047-6052. CrossRef Medline

Fonken LK, Workman JL, Walton JC, Weil ZM, Morris JS, Haim A, Nelson RJ (2010) Light at night increases body mass by shifting the time of food intake. Proc Natl Acad Sci U S A 107:18664-18669. CrossRef Medline

Francl JM, Kaur G, Glass JD (2010) Regulation of vasoactive intestinal polypeptide release in the SCN circadian clock. Neuroreport 21:1055-1059. CrossRef Medline

Gillette MU (1996) Regulation of entrainment pathways by the suprachiasmatic circadian clock: sensitivities to second messengers. Prog Brain Res 111:121-132. CrossRef Medline

Gizowski C, Zaelzer C, Bourque CW (2016) Clock-driven vasopressin neurotransmission mediates anticipatory thirst prior to sleep. Nature 537: 685-688. CrossRef Medline

Granados-Fuentes D, Prolo LM, Abraham U, Herzog ED (2004) The suprachiasmatic nucleus entrains, but does not sustain, circadian rhythmicity in the olfactory bulb. J Neurosci 24:615-619. CrossRef Medline

Grippo RM, Purohit AM, Zhang Q, Zweifel LS, Güler AD (2017) Direct midbrain dopamine input to the suprachiasmatic nucleus accelerates circadian entrainment. Curr Biol 27:2465-2475.e3. CrossRef Medline

Gunaydin LA, Grosenick L, Finkelstein JC, Kauvar IV, Fenno LE, Adhikari A, Lammel S, Mirzabekov JJ, Airan RD, Zalocusky KA, Tye KM, Anikeeva P, Malenka RC, Deisseroth K (2014) Natural neural projection dynamics underlying social behavior. Cell 157:1535-1551. CrossRef Medline

Hermanstyne TO, Simms CL, Carrasquillo Y, Herzog ED, Nerbonne JM (2016) Distinct firing properties of vasoactive intestinal peptideexpressing neurons in the suprachiasmatic nucleus. J Biol Rhythms 31:57-67. CrossRef Medline

Hughes ME, Hogenesch JB, Kornacker K (2010) JTK-CYCLE: An efficient nonparametric algorithm for detecting rhythmic components in genome-scale data sets. J Biol Rhythms 25:372-380. CrossRef Medline

Ibata Y, Takahashi Y, Okamura H, Kawakami F, Terubayashi H, Kubo T, Yanaihara N (1989) Vasoactive intestinal peptide (VIP)-like immunoreactive neurons located in the rat suprachiasmatic nucleus receive a direct retinal projection. Neurosci Lett 97:1-5. CrossRef Medline

Ikeda M, Sugiyama T, Wallace CS, Gompf HS, Yoshioka T, Miyawaki A, Allen CN (2003) Circadian dynamics of cytosolic and nuclear Ca2+ in single suprachiasmatic nucleus neurons. Neuron 38:253-263. CrossRef Medline

Irwin RP, Allen CN (2007) Calcium response to retinohypothalamic tract synaptic transmission in suprachiasmatic nucleus neurons. J Neurosci 27:11748-11757. CrossRef Medline

Jones JR, Tackenberg MC, McMahon DG (2015) Manipulating circadian 
clock neuron firing rate resets molecular circadian rhythms and behavior. Nat Neurosci 18:373-375. CrossRef Medline

Kalsbeek A, Palm IF, La Fleur SE, Scheer FA, Perreau-Lenz S, Ruiter M, Kreier F, Cailotto C, Buijs RM (2006) SCN outputs and the hypothalamic balance of life. J Biol Rhythms 21:458-469. CrossRef Medline

Kuhlman SJ, Silver R, Le Sauter J, Bult-Ito A, McMahon DG (2003) Phase resetting light pulses induce Per 1 and persistent spike activity in a subpopulation of biological clock neurons. J Neurosci 23:1441-1450. CrossRef Medline

Langer I (2012) Mechanisms involved in VPAC receptors activation and regulation: lessons from pharmacological and mutagenesis studies. Front Endocrinol 3:129. CrossRef Medline

LeGates TA, Altimus CM, Wang H, Lee HK, Yang S, Zhao H, Kirkwood A, Weber ET, Hattar S (2012) Aberrant light directly impairs mood and learning through melanopsin-expressing neurons. Nature 491:594-598. CrossRef Medline

Lerner TN, Shilyansky C, Davidson TJ, Evans KE, Beier KT, Zalocusky KA, Crow AK, Malenka RC, Luo L, Tomer R, Deisseroth K (2015) Intactbrain analyses reveal distinct information carried by $\mathrm{SNc}$ dopamine subcircuits. Cell 162:635-647. CrossRef Medline

Lucassen EA, van Diepen HC, Houben T, Michel S, Colwell CS, Meijer JH (2012) Role of vasoactive intestinal peptide in seasonal encoding by the suprachiasmatic nucleus clock. Eur J Neurosci 35:1466-1474. CrossRef Medline

Lucassen EA, Coomans CP, van Putten M, de Kreij SR, van Genugten JH, Sutorius RP, de Rooij KE, van der Velde M, Verhoeve SL, Smit JW, Löwik CW, Smits HH, Guigas B, Aartsma-Rus AM, Meijer JH (2016) Environmental 24-hr cycles are essential for health. Curr Biol 26:1843-1853. CrossRef Medline

Maywood ES, Chesham JE, O'Brien JA, Hastings MH (2011) A diversity of paracrine signals sustains molecular circadian cycling in suprachiasmatic nucleus circuits. Proc Natl Acad Sci U S A 108:14306-14311. CrossRef Medline

Mei L, Fan Y, Lv X, Welsh DK, Zhan C, Zhang EE (2018) Long-term in vivo recording of circadian rhythms in brains of freely moving mice. Proc Natl Acad Sci U S A 115:4276-4281. CrossRef Medline

Meijer JH, Albus H, Weidema F, Ravesloot JH (1993) The effects of glutamate on membrane potential and discharge rate of suprachiasmatic neurons. Brain Res 603:284-288. CrossRef Medline

Michel S, Itri J, Han JH, Gniotczynski K, Colwell CS (2006) Regulation of glutamatergic signalling by PACAP in the mammalian suprachiasmatic nucleus. BMC Neurosci 7:15. CrossRef Medline

Mintz EM, Marvel CL, Gillespie CF, Price KM, Albers HE (1999) Activation of NMDA receptors in the suprachiasmatic nucleus produces light-like phase shifts of the circadian clock in vivo. J Neurosci 19:5124-5130. CrossRef

Morin LP, Allen CN (2006) The circadian visual system, 2005. Brain Res Rev 51:1-60. CrossRef Medline

Muller A, Joseph V, Slesinger PA, Kleinfeld D (2014) Cell-based reporters reveal in vivo dynamics of dopamine and norepinephrine release in murine cortex. Nat Methods 11:1245-1252. CrossRef Medline

Nelson DE, Takahashi JS (1991) Sensitivity and integration in a visual pathway for circadian entrainment in the hamster (Mesocricetus auratus). J Physiol 439:115-145. CrossRef Medline

Nitabach MN, Blau J, Holmes TC (2002) Electrical silencing of drosophila pacemaker neurons stops the free-running circadian clock. Cell 109:485495. CrossRef Medline

Offermanns S, Simon MI (1995) G 15 and G 16 couple a wide variety of receptors to phospholipase C. J Biol Chem 270:15175-15180. CrossRef Medline

Ohta H, Yamazaki S, McMahon DG (2005) Constant light desynchronizes mammalian clock neurons. Nat Neurosci 8:267-269. CrossRef Medline

Piggins HD, Antle MC, Rusak B (1995) Neuropeptides phase shift the mammalian circadian pacemaker. J Neurosci 15:5612-5622. CrossRef Medline

Reed HE, Meyer-Spasche A, Cutler DJ, Coen CW, Piggins HD (2001) Vasoactive intestinal polypeptide (VIP) phase-shifts the rat suprachiasmatic nucleus clock in vitro. Eur J Neurosci 13:839-843. CrossRef Medline

Refinetti R, Lissen GC, Halberg F (2007) Procedures for numerical analysis of circadian rhythms. Biol Rhythm Res 38:275-325. CrossRef Medline

Romijn HJ, Sluiter AA, Pool CW, Wortel J, Buijs RM (1996) Differences in colocalization between fos and PHI, GRP, VIP and VP in neurons of the rat suprachiasmatic nucleus after a light stimulus during the phase delay versus the phase advance period of the night. J Comp Neurol 372:1-8. CrossRef Medline

Sack RL, Auckley D, Auger RR, Carskadon MA, Wright KP Jr, Vitiello MV, Zhdanova IV (2007) Circadian rhythm sleep disorders: part I, basic principles, shift work and jet lag disorders. An American Academy of Sleep Medicine review. Sleep 30:1460-1483. CrossRef Medline

Sakamoto K, Norona FE, Alzate-Correa D, Scarberry D, Hoyt KR, Obrietan K (2013) Clock and light regulation of the CREB coactivator CRTC1 in the suprachiasmatic circadian clock. J Neurosci 33:90219027. CrossRef Medline

Shinohara K, Honma S, Katsuno Y, Abe H, Honma K (1995) Two distinct oscillators in the rat suprachiasmatic nucleus in vitro. Proc Natl Acad Sci U S A 92:7396-7400. CrossRef Medline

Shinohara K, Tominaga K, Inouye ST (1999) Phase dependent response of vasoactive intestinal polypeptide to light and darkness in the suprachiasmatic nucleus. Neurosci Res 33:105-110. CrossRef Medline

Taniguchi H, He M, Wu P, Kim S, Paik R, Sugino K, Kvitsiani D, Fu Y, Lu J, Lin Y, Miyoshi G, Shima Y, Fishell G, Nelson SB, Huang ZJ (2011) A resource of cre driver lines for genetic targeting of GABAergic neurons in cereb cortex. Neuron 71:995-1013. CrossRef Medline

Tischkau SA, Mitchell JW, Tyan SH, Buchanan GF, Gillette MU (2003) $\mathrm{Ca} 2+/ \mathrm{cAMP}$ response element-binding protein (CREB)-dependent activation of Per1 is required for light-induced signaling in the suprachiasmatic nucleus circadian clock. J Biol Chem 278:718-723. CrossRef Medline

Tso CF, Simon T, Greenlaw AC, Puri T, Mieda M, Herzog ED (2017) Astrocytes Regulate Daily Rhythms in the Suprachiasmatic Nucleus and Behavior. Curr Biol 27:1055-1061. CrossRef Medline

Vosko A, van Diepen HC, Kuljis D, Chiu AM, Heyer D, Terra H, Carpenter E, Michel S, Meijer JH, Colwell CS (2015) Role of vasoactive intestinal peptide in the light input to the circadian system. Eur J Neurosci 42:18391848. CrossRef Medline

Webb AB, Angelo N, Huettner JE, Herzog ED (2009) Intrinsic, nondeterministic circadian rhythm generation in identified mammalian neurons. Proc Natl Acad Sci U S A 106:16493-16498. CrossRef Medline

Yamaguchi S, Isejima H, Matsuo T, Okura R, Yagita K, Kobayashi M, Okamura H (2003) Synchronization of cellular clocks in the suprachiasmatic nucleus. Science 302:1408-1412. CrossRef Medline

Zalocusky KA, Ramakrishnan C, Lerner TN, Davidson TJ, Knutson B, Deisseroth K (2016) Nucleus accumbens D2R cells signal prior outcomes and control risky decision-making. Nature 531:642-646. CrossRef Medline

Zhu T, Fang LY, Xie X (2008) Development of a universal high-throughput calcium assay for G-protein-coupled receptors with promiscuous G-protein G $\alpha 15 / 16$. Acta Pharmacol Sin 29:507-516. CrossRef Medline 